between observation and hypothesis it is well worth reading. Some of the theories advanced I regard as highbrow science fiction, I particularly dislike his interpretation of the spreading of Proteus vulgaris. It must be admitted, however, that there is nothing so far published that effectively disposes of them and this edition when compared with the earlier one shows the author to be adaptable enough to adjust to future discoveries as they are made.

The book is notably well produced and the photographs are as good as in the original papers quoted.

W.H.H.

\section{ANATOMY AND PHYSIOLOGY FOR NURSES}

By W. P. Gowland, M.D., F.R.C.S., and JohN CAIRNEY, D.Sc., M.D., F.R.A.C.S. Fourth edition. Pp. 462. Christchurch, New Zealand: N. M. Peryer Ltd. 1955. 45 s.

Here is a book which needs no introduction, previous editions being already well known to the nursing profession. Many of the chapters have been re-written in order to bring the subject matter thoroughly up to date. In addition, the type has been re-set, resulting in a marked improvement in general appearance. There are many clear illustrations to supplement the text.

The authors have written this book primarily for the student nurse, although the chapters on "The Distribution of the Spinal Nerves to the Limbs' and 'The Neuro-Physiology of Vision' have been included for the benefit of students of physiotherapy and orthoptics.

It is unfortunate that the price of $45 \mathrm{~s}$. puts this volume rather out of reach of the average student nurse, as it has already proved itself worthy of more general use in schools of nursing.

R.S.

\section{KINESIOLOGY OF THE HUMAN BODY}

By Arthur Steindler, M.D., (Hon.) F.R.C.S., F.A.C.S., F.I.C.S. Pp. xxiv +708 , illustrated. Oxford: Blackwell Scientific Publications Ltd. 1955. £7 2s. 6d.

In the present work Dr. Steindler elaborates the ideas which he first propounded in his book 'The Mechanics of Normal and Pathological Locomotion.' He is concerned to show that kinesiology, which in his own words 'presents bodily motion as a special case in mechanics,' is a valuable and possibly an indispensable basis for the study of disorders of locomotion. To that end he now attempts an ambitious project-the integration of the theory of kinesiology with the observed facts of various pathological conditions and with the methods for their correction. The first part of the book deals with the physical properties of bone, cartilage connective tissue and muscle in relation to the mechanics and pathomechanics of joint and muscle function. In the second and third parts of the book are considered the mechanics of special regions-spine, pelvis, thorax and limbs-while them gait is considered separately in the fourth part.

The book clearly represents the result of a great: deal of very painstaking work and certainly itsen detailed consideration of applied anatomy anco mechanics forms a very helpful basis for the under-ᄃ standing of locomotor disorders. Very helpful too are those sections dealing with reconstructive procedures for the upper and lower limbs. However, $\Omega$ the bridge connecting the purely mechanical conso siderations to those concerned with pathological conditions remains rather tenuous and the value of Dr. Steindler's more detailed calculations in their $\overrightarrow{-}$ application to clinical practice is still a little doubtful. Indeed, in some sections the attempteft application of the one to the other appears somewhat forced. It is doubtful whether a purely mechanistie. study can serve as a basis for the interpretation of locomotor disorders unless, reinforced by a largew addition of biological theory.

Although the author presents his facts clearly heir presents so many that the book has to be readr slowly and with concentration to assimilate the? mass of information contained in it. The task is made easier by the high standard of production and $z$ of illustration, though the text is marred occasionallye by a few tiresome misprints.

\section{MODERN TRENDS IN BLOOD DISEASES}

Edited by John F. Wilkinson, M.D., M.Sc., Ph. F.R.C.P., F.R.I.C. Pp. viii + 359, with $\overrightarrow{9} 30$ illustrations, two in colour. London: Butter-s worth \& Co., Ltd. I 955 . $£ 3$ ss.

Before embarking on any criticism of this book it must be stated that it is a valuable contribution to modern haematological literature. It is beautifully produced and well illustrated and should be on the shelves of anyone interested in haematology.

According to its editor, the book is a "guide to the present trends of the more important clinical and experimental investigations and research that during the last 20 years, have been pursued actively in one of the biggest branches of medicine-tha? dealing with diseases of the blood and blood forming organs.' The casual reader glancing at the table of contents might be forgiven for assuming that almost all these advances had been made in the hospitals of Manchester, Derby, Glasgow and Newcastle upon Tyne, for I I of the 15 chapters have been written by workers in these hospitals. This: parochial approach seems regrettable, for, althougfO the work done in these hospitals has been considerable, yet it is a pity that no contributions shouls have been included from the Oxford or Cambridgê Schools of Haematology, or from the British Poste graduate School, to mention only three other centres in this country where active research in haematolog has been carried on for a number of years. Nor are there any contributions from the continental schools. American workers have fared better, three chapters being contributed by eminent Americap haematologists. So much for the selection of 